\title{
EL DERECHO RECUPERADO
}

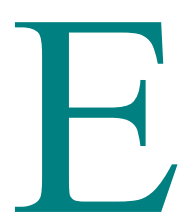

1 artículo «¿La muerte del derecho?»², concebido en 1985 y presentado en Cornell University el año siguiente se refería a los movimientos intelectuales que emergieron en el mundo académico del derecho durante la década precedente. Un aspecto del desafío que entonces enfrenté era el de encontrar un elemento común en estos dos movimientos, uno tan aparentemente distinto al otro, uno que proclama que «el derecho es eficiencia»y el otro que «el derecho es política», uno perteneciente a la derecha, el otro a la izquierda; uno que acepta el rol tradicional de los académicos, el otro más radical y contestatario en su desafío. Sin embargo, la embestida principal del trabajo, tal vez implícita en el título, era negativa, dado que surgía que lo que había en común entre el análisis económico del derecho y la escuela crítica del derecho era una actitud hostil hacia la concepción del derecho aceptada confiadamente por la práctica profesional en los años 60. Rechazaban lo que yo estaba preparado a defender, una visión según la cual el derecho es una expresión de valores públicos.

Aquí les ofrezco una actualización de esa idea, una relación acerca de lo que ocurre en el mundo académico en la actualidad y, asombrosamente, mi ánimo es más optimista. Los peligros de los que hablaba

${ }^{1}$ Profesor Alexander M. Bickel de Derecho Público de la Universidad de Yale. Este ensayo se basa en una presentación ante la Jurisprudence Section of the American Association of Law Schools, en Nueva Orleans, el 8 de enero de 1989. El tema del encuentro fue mi artículo «¿La Muerte del Derecho?» Agradezco al profesor Gary Minda, quien presidió el panel y a los participantes, profesores Clare Dalton, Duncan Kennedy, Frank Michelman y George Priest. También agradezco a dos de mis estudiantes, Lawrence Douglas y Robert Schapiro. Este ensayo fue publicado por primera vez en Cornell Law Review, volumen 74, número 2, enero de 1989.

272 Cornell Law Review 1 (1986). Trad. Cast. en el no 10 (1991) de Doxa, a cargo de Gabriel Bouzat. 
antes parecen menos amenazantes. En parte, esto se debe al hecho de que el análisis económico del derecho, y especialmente esa rama del movimiento que reclama como tarea para el derecho la de perfeccionar o imitar al mercado, parece haber llegado a su cima. Nada del entusiasmo y compromiso generado por los primeros trabajos de Richard Posner existe hoy en día. Hay poco interés en la hipótesis de la eficiencia, y su invocación se enfrenta con un sentimiento de incredulidad cada vez mayor. No hay duda de que la influencia de la economía en el análisis del derecho persistirá, algunos presupuestos siguen alimentando esta empresa con extrema sofisticación; los estudiosos dedicados a este trabajo de tipo interdisciplinario están bien guarnecidos en los cuerpos académicos; y cierto número de defensores de la hipótesis de la eficiencia, incluido el mismo Posner, han sido elevados a los tribunales. Pero en general, el hechizo parece haberse deshecho. Más que intentar redefinir la función o el objeto del derecho de un modo global, mi corazonada es que el método económico será utilizado, como previó Bruce Ackerman ${ }^{3}$, de un modo más tecnocrático y modesto. Será utilizado, por ejemplo, para indicar la decisión apropiada en casos en los que el contenido manifiesto del derecho es el de proteger o perfeccionar el mercado (leyes antimonopólicas) o, de un modo más positivo, para explicar el comportamiento de actores, quienes de hecho operan en mercados bien organizados (la industria del seguro).

Mi punto de vista acerca de la escuela crítica del derecho es, de algún modo, diverso. Este movimiento no ha llegado a la cúspide y sigue teniendo influencia en el mundo académico. Por lo que yo sé, ha habido pocos reclutas entre los profesores, pero el interés de los estudiantes en el movimiento se mantiene con fuerza e intensidad. Esto es particularmente cierto en Yale, donde las prácticas peculiares para admitir nuevos profesores hacen sentir a los alumnos que se los deja de lado de algo delicioso y perverso. Pero creo que los estudiantes de todas partes sienten una afinidad especial hacia la escuela crítica del derecho. En los anos 60, la Corte Warren habló del idealismo de los jóvenes y produjo una generación de abogados determinados a ver lo mejor que hay en las leyes, pero veinte años de Burger y Rehnquist nos legaron un cuerpo doctrinario incapaz de inspirar a alguien y que en cambio nos invita, utilizando la fórmula de Ricoeur ${ }^{4}$, a la hermenéutica de la sospecha. La escuela crítica del derecho es presa de este sentimiento de desencanto, siempre lo ha sido, pero ahora me doy cuenta de que la

\footnotetext{
${ }^{3}$ Ver Ackerman, Law, Economics and the Problem of Legal Culture, 1986 Duke Law Journal 929.

${ }^{4}$ Ver Paul Ricouer, Freud and Philosophy, An Essay on Interpretation 26-30 (1970).
} 
sospecha puede tomar muchas formas, no todas ellas negativas. En mi trabajo anterior permití a Duncan Kennedy y Roberto Unger hablar en nombre del movimiento, pero en tanto el movimiento ha crecido y madurado, sus opiniones han cambiado y, más aún, su hegemonía ha terminado. Ahora, diez años más tarde, la escuela crítica del derecho se ha convertido en un movimiento más pluralista y multifacético, y en trabajos tales como los de Peter Gabel y Frank Michelman no veo una amenaza sino un importante aporte al derecho.

«El derecho es política». Siempre he tomado este slogan como la llave a la escuela crítica del derecho, y en él basé mi hostilidad al movimiento pero, como señaló Frank Michelman en una reciente conferencia auspiciada por Cornell University ${ }^{5}$, puedo haber malinterpretado lo que quiere significar. Dado que creí que al proclamar que «el derecho es política», los sostenedores de la escuela crítica del derecho tenían en mente una forma más bien básica de política, política como comportamiento de mercado, como nada más que la expresión de intereses y preferencias. De hecho, ellos, o al menos algunos académicos de la escuela crítica del derecho, pueden haber tratado de abrazar la posibilidad de una visión más noble e idealista de la política, una más cercana a una expresión de valores públicos o de principios o de derechos, antes que preferencias privadas. Esta concepción de la política está asociada con la tradición republicana clásica que está siendo redescubierta y revivida por un conjunto de académicos del derecho. Frank Michelman está al frente de este grupo de académicos, si bien se ha planteado la tarea de intentar fusionar el pensamiento de la escuela crítica del derecho con el republicanismo cívico ${ }^{6}$.

Desde luego, mi concepto previo acerca del tipo de política que vislumbran los académicos de la escuela crítica del derecho no está basado en el perverso deseo de reservar para el derecho una actividad totalmente idealista. Más bien surge de la lectura del trabajo de Duncan Kennedy «La contradicción fundamental, el cual, tal como lo entendí, coloca dentro de toda estructura normativa dos impulsos o fuerzas conflictivas -el amor de unos y el temor de otros- que pujan en direcciones opuestas y por lo tanto convierten todo valor, derecho o 256 (1989).

${ }^{5}$ Michelman, F., Bring the Law to Life: A Plea for Disenchantment, 74 Cornell Law Review

${ }^{6}$ Ver Michelman, The Supreme Court, 1985 Term -Foreword: Traces of Self Government, 100 Harvard Law Review 4 (1986). También contribuyó con un ensayo al simposio sobre el nuevo republicanismo del Yale Law Journal, ver Michelman Law's Republic, 97 Yale Law Journal 1493 (1988). 
principio en indeterminado e inútil como guía para actuar o juzgar ${ }^{7}$. La «contradicción fundamental» deconstruye toda estructura normativa, sea legal o política, y no deja nada en su base excepto intereses y preferencias. Puede ser cuestionado si estaba en lo cierto al asignar un lugar tan importante a la idea de Kennedy pero, a modo de defensa, permítanme decir que el mismo Michelman, en su anterior trabajo, publicado en Nomos $^{8}$, enfatizaba la noción de «contradicción fundamental» y aparentemente con los mismos motivos que yo tenía, es decir, proveer un fundamento teórico para la versión fuerte de la tesis de la indeterminación (que niega en cualquier caso la posibilidad de una respuesta correcta).

Llegado a este punto, la posición de la escuela crítica del derecho respecto a estas tesis es, para expresarlo contemplativamente, oscura Duncan Kennedy renunció a la «contradicción fundamental» ${ }^{9}$ y más recientemente a la tesis misma de la indeterminación fuerte $^{10}$. Frank Michelman sostiene (en conversaciones) que aún cree en la «contradicción fundamental» y por lo tanto todavía suscribe a la tesis de la indeterminación fuerte, pero de ser así, es difícil comprender como puede seguir proponiendo una noción idealista, o como él dice, de buena fe en la política. Si un juicio indeterminado, digamos respecto a que es lo que está bien o lo que es justo, es posible en el terreno de la política, es difícil comprender por qué tales juicios no son aplicables al derecho ¿Si la buena fe en política es posible, por qué no lo es respecto al derecho?

En su disertación en Cornell University, Michelman parece estar más atraído por el pragmatismo de Richard Rorty que por la «contradicción fundamental» de Duncan Kennedy. Michelman caracteriza su punto de vista acerca de una política idealista como una política pragmática $^{11}$. Pero este giro hacia la postura de Rorty es insuficiente

${ }^{7}$ Ver Kennedy, Duncan, The Structure of Blackstone's Commentaries, 28 Buffalo Law Review 205, 211-13 (1979).

${ }^{8}$ Michelman, Justifications (and justifiability) of Law in a Contradictory World, en 28 Nomos: Justification 71 (J Pennock \& J. Chapman, eds 1986).

${ }^{9}$ Gabel \& Kennedy, Roll Over Beethoven, 36 Stanford Law Review 1, 15-18 (1984).

${ }^{10}$ Kennedy, en una consideración fenomenológica de la aplicación del derecho por los jueces, trata a los principios no como metafísicamente inestables, sino como impedimentos psicológicos para tomar decisiones acertadas y reconoce que en ciertas situaciones los jueces pueden experimentar el derecho como algo determinado, como una «objetividad percibida». Kenndy, Freedom and Constraint in Adjudication: A Critical Phenomenology 36 Journal of Legal Education 518,560-562 (1986). Kennedy, en su respuesta a Warren Lehman durante el encuentro de la Jurisprudence Section of the American Association of Law Schools en enero de 1989 disolvió su compromiso con la tesis de la indeterminación fuerte de modo terminante.

${ }^{11}$ Michelman, supra nota 5, páginas 257-8. 
para proveer a la tesis de la indeterminación con un fuerte apoyo teórico. Como señala Stanley Fish ${ }^{12}$, lo que niega el pragmatismo de Rorty no es la posibilidad de un juicio determinado, sino la existencia de un fundamento trascendente para juicios éticos. Como sostienen los pragmáticos, no hay nada «allí afuera», no hay una propuesta con la cual todos podamos fácilmente acordar sin cuestionar la determinación del derecho o sin desafiar de cualquier otra forma su integridad. La invocación a Rorty no salva la tesis de la indeterminación de los zigs zags de Kennedy, pero sugiere que la tesis es de segundo orden, un instrumento para apoyar la idea más importante y superior, o sea, que «el derecho es política».

El segundo error en mi ensayo previo fue el de suponer que el verbo «es» en el slogan «el derecho es política» tenía por objeto establecer una identidad entre las dos esferas en tanto que, como señaló Michelman en su conferencia en Cornell y como sugirió recientemente en un estudio Peter Gabel ${ }^{13}$, el slogan podría, de hecho, ser tomado en cuenta con más modestia, sin sostener una reducción radical de una esfera a la otra, sino para debilitar la continuidad de ambas y para recordarnos lo indispensable de la política en el derecho. Desde luego, no es necesario pertenecer al movimiento de la escuela crítica del derecho para comprender la continuidad entre las dos esferas, o para recordarnos a los abogados la importancia de la política; un republicanismo llano del tipo propuesto por Michael Waltzer es suficiente ${ }^{14}$. Pero percibo en el periplo intelectual de Frank Michelman, en el cual una fascinación inicial con la escuela crítica del derecho maduró en un compromiso con el republicanismo cívico, algo más que un truco biográfico. Mas allá de lo que podamos decir acerca de la escuela crítica del derecho, debemos reconocer que durante la década pasada ha sido la fuerza prominente en el ambiente académico subrayando la importancia de lo político.

Continúo creyendo que el derecho es una forma particular de actividad humana, una actividad que, como Ronald Dworkin y otros han sostenido de unos años a esta parte, difiere de la política y aún de

${ }^{12}$ Fish, Interpretation and the Pluralist Vision, 60 Texas Law Review 495 (1982).

${ }^{13}$ Peter Gabel, The defeat of Michael Dukakis and the Transformative Possibilities of Legal Culture (ensayo presentado en el seminario de teoría legal, Yale Law School, 15 de diciembre de 1988 -versión abreviada en 4 Tikkun 13, 1989).

${ }^{14}$ Walzer, desde la vereda opuesta, lo presentó de la siguiente forma: «La política es soberana, pero no es auto-suficiente» Walzer. Flight From Philosophy, New York Review of Books, 2 de febrero de 1989, en 42, 43 (releyendo a B. Barber, The Conquest of Politics: Liberal Philosophy in Democratic Times, 1988) Walzer es una de aquellas personas que en estos tiempos parece tener una actitud conciliatoria. Comparen su anterior crítica del derecho en Democracy and Philosophy, 9 Political Theory 379 (1981). 
una política altamente idealizada de manera importante. Los actores políticos pueden y con frecuencia hacen planteos de justicia, pero esto no ocurre necesariamente. Afirmar que cierta acción o política es buena, o es en beneficio de la comunidad, será suficiente para el campo de la política. A veces es suficiente con que un político le dé a la gente lo que quiere, simplemente porque es lo que la gente quiere. Los jueces, por otro lado, no tienen otra autoridad, salvo la de decidir lo que es justo, y obtienen el derecho a hacerlo de las normas procesales que rodean su cargo y limitan el ejercicio de su poder. Sin embargo, insistir en estas diferencias entre el derecho y la política no implica negar que existen importantes conexiones entre ambos.

Peter Gabel ha sugerido una de estas conexiones. Visitó New Haven en diciembre de 1988 con una actitud conciliatoria, esperanzado en poder construir un nuevo movimiento progresista dentro del derecho. Utilizando la derrota de Dukakis en la elección de noviembre de 1988 para iniciar su argumentación, Gabel insistió en que las invocaciones a derechos nunca pueden ser efectivas o atractivas a menos que estén fundadas en una perspectiva social más amplia, como lo estaban durante la era de los derechos civiles, esa época de oro del derecho norteamericano ${ }^{15}$. Estoy de acuerdo con este punto de vista y con la aspiración subyacente, si bien deseo expresar la idea de forma algo diferente. Yo diría que la aplicación del derecho por parte de los jueces depende de una comprensión social que contempla la existencia de valores públicos, dado que sin dicha comprensión no tendría sentido la institución. La aplicación del derecho por parte de los jueces no es más que una institución social para interpretar y hacer efectivos valores públicos. Acepto además que la comprensión social a la que hacía referencia Gabel no es propiedad particular de los abogados, sino que su ámbito de pertenencia es el cuerpo político y, entonces, puede considerársela apropiadamente como «política». Ciertamente, el derecho tiene un papel importante que cumplir en generar esa comprensión social. Brown v. Board of Education ${ }^{16}$, por ejemplo, presuponía y también profundizaba el compromiso hacía la igualdad racial que estigmatizaba a la sociedad norteamericana en los primeros anos de la década de 1960, y asimismo convirtió en legítimo un ejercicio fuerte del poder judicial ${ }^{17}$. Pero no hay razones para dar excesiva

${ }^{15}$ Ver P. Gabel, supra, nota 13.

${ }^{16} 347$ U S 483 (1954). Brown v. Board of Education (Estado de Kansas) fue una decisión histórica de la Corte Suprema, por la cual se dejó de lado la doctrina de «separados pero iguales» («separate but equal») en materia educativa. Estableció un standard que apuntaba a la integración de los negros y blancos en las escuelas.

${ }^{17}$ Ver Fiss, supra, nota 2 página 15. 
importancia a este punto. El poder judicial no es la única institución con este especial poder generativo, y en todo caso, ningún tribunal, aún presidido por Earl Warren, puede tener éxito en generar esta comprensión social por sí mismo.

En un nivel más abstracto, el derecho está vinculado a la política mediante ciertos aspectos técnicos del procedimiento de aplicación del derecho que requieren que la judicatura -como una condición de su legitimidad- escuche a todas las partes agraviadas y que entonces justifique públicamente su decisión. La organización y la actividad política son a veces necesarias para formular y presentar cargos ante la judicatura, para hacer conscientes a las víctimas de su disfortuna, para contar con la posibilidad de modificarla y para enfrentar las respuestas insatisfactorias que a veces dan las judicaturas a los agraviados, como en el caso Plessy v. Fergusson ${ }^{18}$ o Bowers v. Hardwick ${ }^{19}$. A veces la actividad política se desarrolla en forma exaltada y desordenada y esta también es una lección de la época de los derechos civiles. Los jueces de los tribunales debían escuchar a la gente en los mostradores de los bares de Greenville, en las calles de Birmingham y en los caminos de Selma a Montgomery, y sus respuestas surgieron acordes a este contexto. Los jueces sabían que debían reexaminar las posiciones que habían sostenido y debían estar seguros de que sus respuestas fueran acordes a los agravios.

Finalmente, el énfasis en la política que propone la escuela crítica del derecho puede ser un sano correctivo a la tendencia natural de muchos académicos del derecho (entre los que me incluyo) a centrar su atención en la conducta de los tribunales y de ignorar las diversas formas -nombramientos, estatutos, enmiendas constitucionales- mediante las cuales el proceso político crea el campo en el cual los tribunales operan. La batalla en la Comisión de Acuerdos del Senado sobre la nominación de Bork, para tomar un ejemplo obvio, fue uno de los eventos más decisivos para moldear la estructura general dentro de la cual deben actuar los tribunales en los próximos años -no simplemente porque la consecuencia fue negarle un lugar a Robert Bork en la Corte Suprema- sino porque la decisión de la Comisión y del Senado

${ }^{18} 163$ U.S. 537 (1896). El fallo Plessy v. Fergusson estableció la doctrina, posteriormente rechazada, de «separados pero iguales», como producto de las enmiendas posteriores a la Guerra Civil.

${ }^{19} 487$ U.S. 186 (1986). El fallo Bowers v. Hardwick estableció que la legislación anti sodomía del estado de Georgia es constitucional y que no viola el derecho a la privacidad. 
se basó en cuestiones que tienen importantes implicaciones para el derecho a la privacidad, la Primera Enmienda, los casos relevantes de derechos civiles, y en ese sentido, todo el legado de la Corte Warren ${ }^{20}$. Sólo Dios sabe si ese hecho puede considerarse «legal»o «político».

La escuela crítica del derecho considerada bajo esta perspectiva, es decir, como aceptando una faz más idealista de la política y reconociendo la continuidad de lo político y de lo legal sin reducir todo el derecho a la política, parece menos amenazante. En el proceso de elaboración y de maduración a manos de personas como Michelman y Gabel, la escuela crítica del derecho ha perdido bastante de su nivel de seducción radical, pero al mismo tiempo aparece como menos destructiva. Hay diferencias que merecen ser discutidas (siempre las hay), pero es difícil ver aquí al movimiento que pone en peligro al derecho o algo que se le parezca. Por el contrario, considerando donde se encuentra el derecho constitucional norteamericano en la actualidad, y a donde aparentemente se dirige, el énfasis en la política y sus posibilidades idealistas puede ser precisamente lo que necesitamos.

Este cambio en la escuela crítica del derecho, o mi comprensión del mismo, ha sido acompañado por otro desarrollo de ideas -el surgimiento del feminismo- que le ha infundido una nueva vida al derecho y regeneró sus posibilidades idealistas. A mediados de los años 80, en el momento de mi disertación previa, el feminismo era apenas considerado en el mundo académico, pero en los últimos tres o cuatro años ha emergido como un movimiento intelectual separado y brillante en el mundo del derecho, capturando el interés de la izquierda y atrayendo para sí mucha de la energía y atención de la que en un momento gozó la escuela crítica del derecho. El feminismo ha absorbido de la escuela crítica del derecho una de sus importantes fuentes de poder, y en cierto modo no podemos predicar lo mismo de la escuela crítica del derecho, aun de aquellas facciones que proponen una doctrina más moderada; el feminismo ha combinado la hermenéutica de la sospecha con un mayor compromiso hacia una visión afirmativa del derecho.

Una parte del proyecto feminista, tal como lo entiendo, es radicalmente crítico. Intenta demostrar que las reglas del derecho aparentemente «neutrales» o «imparciales», tales como la doctrina del consentimiento en la violación, no son ni «neutrales» ni imparciales» en lo más

${ }^{20}$ Ver «Nomination of Robert H. Bork to he Associale Justice of the Supreme Court of the United States, 1987: Hearing Before the Senate Comm on the Judiciary, 100th Congress, 1st. Sess (1987); Morris, The Grammar of Advice and Consent: A Senate Confirmation of Supreme Court Nominees, 38 Drake Law Review (a ser publicado en mayo de 1989). 
mínimo, sino más bien expresiones de los intereses o percepciones de aquellos que, por siglos, han estado a cargo de nuestro sistema legal, es decir, los hombres. El derecho ha servido como un instrumento de subordinación. Al intentar desmitificar el derecho, el feminismo y la escuela crítica del derecho se superponen (si bien algunos autores de la escuela crítica del derecho, en particular Morton Horowitz y Mark Tushnet tienden a definir, en un estilo marxista, a la clase dominante más en términos económicos que de género). De hecho, creo que fueron las preocupaciones de las feministas las que dieron a la escuela crítica del derecho buena parte de su atractivo y cariz organizacional, especialmente a fines de la década del 70 y principio de la década del 80, cuando las feministas no habían logrado aun una voz independiente dentro del mundo académico del derecho. El feminismo era el programa implícito de la escuela crítica del derecho. Comentando esta especulación, Robin West señaló recientemente (también durante una conversación en New Haven) que estaba sorprendido por la satisfacción feminista del último ejercicio de «desmalezamiento» ${ }^{21}$ de Mark Kelman: está basado en su totalidad en las ideas de MacKinnon.

Si bien la escuela crítica del derecho y el feminismo parecen superponerse en el hecho que ambas corrientes suscriben a un programa de desmitificación, el feminismo difiere de la escuela crítica del derecho en dos aspectos importantes. En primer lugar, tiene una expresión afirmativa en su ejercicio: el fin de la crítica no es la crítica, como lo es para las expresiones más virulentas de la escuela crítica del derecho, sino más bien el logro de una verdadera y sustancial igualdad para las mujeres. Este compromiso igualitario no sólo aporta un elemento para un ejercicio de deconstrucción, también le pone un límite. Dado cierto hecho demográfico en cuanto a la constitución del foro de abogados, puede haber motivos para sospechar del derecho, pero finalmente, sólo aquellas leyes o doctrinas que plausibiemente pueden considerarse como responsables de desigualdades son atacadas por contener discriminaciones ocultas. Por lo tanto, mientras las leyes antidiscriminatorias son fácilmente aceptadas por la corriente deconstructiva de la escuela crítica del derecho -como las leyes contractuales y de propiedad- el feminismo admite otras distinciones.

En segundo lugar, el compromiso feminista con la igualdad no se limita al derecho, sino que abarca todas las instituciones sociales, incluyendo algunas sumamente conocidas, como la familia, el mercado y varias prácticas íntimas e industrias públicas (prostitución y pornografía) que tratan a la mujer como un objeto sexual. El feminismo ataca

${ }^{21}$ M. Kelman, A Guide to Critical Legal Studies (1987). 
la subordinación de la mujer en todas sus formas. Más aún, en este proyecto reformista, el feminismo contempla un importante rol para el derecho. Algunos buscan utilizarlo para asegurar igualdad en el proceso de alocación; otros, tratando de cosechar los logros del movimiento de los derechos cívicos, insisten en una igualdad estructural ${ }^{22}$. En cualquiera de estos casos, el reclamo feminista no es un reclamo de intereses, sino de justicia. Las feministas creen en los derechos y el derecho -un derecho limpio e incorrupto- de un modo y en un grado tal que no es igual al de los que abogan por la escuela crítica del derecho. El fallo Roe v. Wade ${ }^{23}$ es defendido por considerarselo correcto y justo y no meramente como una cuestión de intereses.

Por cierto, hay varios temas en la literatura feminista que pueden indicar un punto de vista opuesto. Uno de estos es la denuncia sobre la objetividad en los artículos Signs ${ }^{24}$ de Catherine MacKinnon. Sin embargo, no tomo en considereración esta afirmación como un reclamo teórico -según el cual la objetividad en el derecho no es posible- dado que tal afirmación debería considerarse objetiva y por ende contradictoria. Además socavaría su crítica respecto a la jerarquía de los géneros, dado que la misma se basa en un tipo de idea objetiva respecto a la justicia o la igualdad. Por lo tanto, me parece que la obra de MacKinnon no debería interpretarse como un reclamo teórico acerca de la posibilidad de objetividad, sino como una cuestión histórica más limitada, o sea, que dadas las condiciones sociológicas bajo las cuales las leyes han sido hechas e interpretadas -la casi absoluta exclusión de las mujeres de este proceso- convierten a la pretendida objetividad del derecho en un falso pretexto o una mascarada de los intereses de aquellos que hicieron las leyes (los hombres ${ }^{25}$. Si bien la duda de base histórica acerca de la objetividad del derecho no es un problema menor, no deja de admitir la posibilidad del derecho. Para algunos, el derecho puede ser sólo eso, una posibilidad teórica, una quimera filosófica, a pesar de que en varias victorias judiciales, tales como Roe v. Wade, y

${ }^{22}$ Discutí esta distinción en Coda, 38 University of Toronto Law Journal 229, 231-35 (1988).

${ }^{23} 410$ U.S. 113 (1973) El fallo Roe v. Wade reconoció el derecho de una mujer a decidir acerca del aborto, basándose en la idea que la Constitución garantiza el derecho a la privacidad.

${ }^{24}$ Mackinnon, Feminism, Marxism, Method and the State: Toward Feminist Jurisprudence, 8 Signs 635 (1983); Mackinnon, Feminism, Marxism, Method and the State: an Agenda for Theory, 7 Signs 515 (1982). Ver, además, Toward a Feminist Theory of the State, Harvard University Press, (1989) de la misma autora.

${ }^{25}$ Ver C. Mackinnon, Feminism Unmodified 55 (1987); ver también Feminist Discourse, Moral Values and the Law -A Conversation-, 34 Buffalo Law Review 11, 87 n. 34 (1985). 
en las apreciaciones jurídicas de Catherine MacKinnon, otros encuentran la posibilidad teórica convertida en concreta realidad. Catherine MacKinnon, sensible a la diferencia entre la política y el derecho y decidida a descubrir el potencial liberador oculto en el derecho a través de la práctica jurídica que ha desarrollado, es ahora una fuente de inspiración para toda una generación de estudiantes de derecho. Ella les ha mostrado lo que pueden hacer con el derecho, no sólo por el poder que representa, sino además como una forma especialmente disciplinada del poder.

Muchas feministas, incluida MacKinnon, han enfatizado la importancia del «despertar de conciencias» ${ }^{26}$, pero no encuentro una inconsistencia entre esta noción y la posibilidad del derecho y sus compromisos objetivos. El «despertar de conciencias» definido como el encuentro de mujeres (y sólo mujeres) para compartir y reflexionar acerca de sus experiencias personales no es otra cosa que una técnica epistemológica. Es una forma de llegar a conocer la verdad, o de descubrir las discriminaciones ocultas y situaciones de opresión en diversas prácticas personales o instituciones sociales, incluido el derecho. En cierto punto, Mackinnon describe el «despertar de conciencias» como «el» método feminista $^{27}$, pero soy escéptico tanto respecto a su eficacia como en cuanto a su importancia para el proyecto feminista, o aún a su eficacia. No se ha presentado ningún argumento persuasivo para explicar por qué es el único método para descubrir la verdad, o siguiera alguno particularmente promisorio, dado el cariz fuertemente constructivista de los temas de Mackinnon y otras feministas, que tienden a considerar todo, incluso nuestra conciencia, como construido por poderosas fuerzas sociales. No veo como el mero hecho de compartir experiencias puede liberar una conciencia tan fuertemente determinada por lo social.

Finalmente, están los trabajos de Carol Gilligan ${ }^{28}$. Gilligan no entra (y presumibiemente no lo hará) en el debate acerca de la objetividad, pero sin embargo introduce en la deliberación moral una perspectiva -la ética del cuidado afectivo- que debe ser contrastada con la perspectiva que enfatiza la justicia o los derechos como han sido tradicionalmente entendidos. La obra de Gilligan ha tenido una enorme influencia en el mundo académico y en el movimiento feminista, y algunos la consideran como un repudio a las aspiraciones objetivistas

${ }^{26}$ Mackinnon, Feminism, Marxism, Method and the State: An Agenda for Theory, supra, nota 24, páginas 519-520, 543-44.

${ }^{27}$ Id. págs. 519-520.

${ }^{28}$ C. Gilligan, In a Different Voice: Psychological Theory and Women's Development (1982). 
del derecho: la búsqueda de la justicia. Carrie Menkel-Meadow ${ }^{29}$, por ejemplo, ha utilizado la obra de Gilligan como una base para criticar la aplicación judicial del derecho, al menos en su expresión básica. De un modo semejante al programa de Kennedy de aplicación judicial del derecho particularizada ${ }^{30}$, Menkel-Meadow argumenta a favor de mecanismos alternativos para solucionar disputas, que no tienen por objeto la justicia sino la solución de diferencias. Esto me sorprende como una incorrecta lectura de la obra de Gilligan.

Gilligan se propuso recuperar una perspectiva perdida, algo que había sido ignorado o dejado de lado por la filosofía moral contemporánea (Rawls) y por la psicología desarrollista (Kohlberg). Una vez recuperada, la ética del cuidado afectivo no debe tomarse como un ideal competitivo que busca desplazar al derecho o su compromiso con la justicia, sino como un ideal suplementario que enriquece y nutre al derecho. En su momento más utópico -cuando relata la historia de los dos niños, uno que desea jugar a los piratas, otro que desea jugar a los vecinos y que encuentran un nuevo juego, un tercer camino, que hace felices a ambos ${ }^{31}$ - Gilligan vislumbra una nueva práctica o arreglo institucional que sintetice las perspectivas del cuidado afectivo y de la justicia. No creo que esta interpretación de su trabajo signifique un repudio al derecho o a su compromiso con la justicia, sino una expresión de deseo a partir de la cual el compromiso de la justicia con el derecho puede ser mejorado o perfeccionado.

Visto desde esta perspectiva, el surgimiento del feminismo me impresiona como un movimiento enteramente saludable. El feminismo retorna la posta del movimiento por los derechos civiles, inyectando nueva vida y energía a la noción del derecho como ideal público, el tipo de vida y energía de que gozó en los años sesenta pero no más allá de ese momento. Me percato, sin embargo, de que dado el poder político de las mujeres, que se manifestó dramáticamente en el debate sobre la nominación del Juez Bork, no debe ponerse mucho énfasis en el derecho. El derecho es importante, sin duda indispensable, pero tal vez no tan importante como fue el movimiento para asegurar el derecho de los negros (o como lo es actualmente para el movimiento para asegurar

${ }^{29}$ Ver, por ejemplo, Menkel-Meadow, Portia in a Different Voice: Speculations on a Women's Lawyering Process, 1 Berkeley Women's Law Journal 39 (1985).

${ }^{30}$ Ver Kennedy, Freedom and Constraint in Adjudication: A Critical Phenomenology, supra, nota 10; Kennedy, Distributive and Paternalist Motives in Contract and Tort Law, with Special Reference to Compulsory Terms and Unequal Bargaining Power, 41 Maryland Law Review 563, 646-49 (1982).

${ }^{31}$ Ver, por ejemplo, Feminist Discourse, Moral Values and the Law -A Conversation-, supra nota 25 página 45 . 
los derechos de los homosexuales o las lesbianas). En este contexto, entonces, cuando el movimiento femenino es el movimiento del día, puede no haber razones para negar la hermenéutica de la sospecha del derecho, y todas las razones posibles en el mundo para enfatizar la importancia de la política, en particular la que considera a los demás en su variante idealizada.

«El derecho es política», como técnica para alcanzar esos fines es, tal vez, demasiado para mi gusto, pero encuentro que es menos preocupante en un contexto dominado por las mujeres, antes que por el movimiento de los derechos civiles. La apreciación de la posición única de las mujeres y de su poder también me permite comprender por qué aquellos que de hecho suscriben la idea de que «el derecho es política» están particularmente ansiosos por establecer relaciones de colaboración con las feministas. No es casual que cuando Frank Michelman toma en consideración la tarea de explicar cómo sería el rol de una judicatura activa en su república -dejo de lado la cuestión de si es «derecho» o «política»- se apoya fuertemente en la obra de algunas de las principales figuras del movimiento feminista, incluidas Drucilla Cornell, Sylvia Law, Bell Hooks, y sobre todo, Martha Minow, y entonces estructura el rol de la judicatura en términos de potenciar la perspectiva de aquellos que de otro modo serían ignorados. «Los jueces», explica Michelman, «tal vez gozan de una ventaja por su situación sobre el común de la gente para escuchar las voces de aquellos que están en los márgenes $\rangle^{32}$. En este giro argumental, Michelman refleja un tema que domina los trabajos actuales del feminismo y por lo tanto sugiere que no sólo intenta combinar la escuela crítica del derecho con el republicanismo cívico, sino que además agrega un tercer ángulo a su inusual motivación: el feminismo.

$\mathrm{Al}$ decir esto, no pretendo sugerir que la escuela crítica del derecho se ha convertido en una rama del feminismo (si bien todo es posible). Tampoco quiero menospreciar en modo alguno el proyecto de Michelman. De su anterior trabajo acerca de la protección de los pobre $^{33}$ hasta el presente no hay otro académico cuya obra me haya impactado de tal modo o haya sido para mí de tanta inspiración. Lo que quiero decir es que hoy, contrariamente a los que temí años atrás, puedo concebir la posibilidad de nuevas formas de colaboración entre los académicos de la escuela crítica del derecho, las feministas y aquellos románticos que aún tienen su vista fija en las luchas de los derechos civiles de los años

${ }^{32}$ Michelman, Law's Republic, supra nota 6, 1537.

${ }^{33}$ Ver Michelman, The Supreme Court, 1968 Term-Foreword: On Protecting the Poor Through the Fourteenth Amendment, 83 Harvard Law Review \& (1969). 
sesenta y que ven al derecho como la expresión de valores públicos. Hoy puedo imaginar nuevas formas de coexistencia pacífica y productiva que, por extraño que parezca, dado lo ocurrido en las elecciones de 1988, pueden desplazar al sueño de Peter Gabel de un renacimiento progresista un paso más cerca de la realidad.

(Traducción de Roberto de Michele) 